\title{
Vasculopatia Livedóide: Uma Revisão de 5 Casos Clínicos
}

\author{
Rui Pedro Santos ${ }^{1}$, Olga Ferreira², Celeste Brito ${ }^{2}$ \\ 'Interno de Serviço de Dermatovenereologia, Hospital de Braga, Braga, Portugal \\ ${ }^{2}$ Especialista de Serviço de Dermatovenereologia, Hospital de Braga, Braga, Portugal
}

RESUMO - A vasculopatia livedóide é uma dermatose trombo-oclusiva incomum que se manifesta com lesões eritemato-purpúricas punctiformes e úlceras extremamente dolorosas, preferencialmente no terço inferior das pernas. Apresentam-se cinco doentes com vasculopatia livedóide, três homens e duas mulheres, com idades entre os 24 e os 54 anos, sem antecedentes pessoais relevantes. O diagnóstico foi confirmado por biópsia em quatro casos. $O$ estudo de trombofilias revelou heterozigotias do gene MTHFR em dois casos. A terapêutica efetuada pelos cinco doentes incluiu venotrópicos, antitrombóticos, anticoagulantes, imunossupressores e imunoglobulina endovenosa. Apenas um doente mantém controlo insatisfatório da doença. A etiopatogenia da vasculopatia livedóide permanece incerta. Pode surgir no contexto de trombofilias hereditárias ou adquiridas, autoimunidade ou neoplasias. Estas alterações deverão ser excluídas, embora grande parte dos casos permaneça idiopática, o que contribui para a dificuldade na abordagem terapêutica. Os autores pretendem salientar a importância do Dermatologista no diagnóstico de uma patologia provavelmente subdiagnosticada, mas que condiciona morbilidade significativa.

PALAVRAS-CHAVE - Arteriopatias Oclusivas; Livedo Reticular; Úlcera da Pele; Úlcera de Perna.

\section{Livedoid Vasculopathy: A Review of 5 Clinical Cases}

ABSTRACT - Livedoid vasculopathy is an unusual thrombo-occlusive dermatosis that manifests with punctiform erythemato-purpuric lesions and extremely painful ulcers, preferably in the lower third of the legs. We report five patients with livedoid vasculopathy, three men and two women, aged between 24 and 54 years, with no relevant personal background. The diagnosis was confirmed by biopsy in four cases. Study of thrombophilias revealed heterozygosity of the MTHFR gene in two cases. Treatment was diversified and included among others, venothropics, anticoagulants, antithrombotics, immunosuppressants and intravenous immunoglobulin. Only one patient has unsatisfactory control of the disease. Livedoid vasculopathy etiopathogenesis remains uncertain. It may occur in the context of hereditary or acquired thrombophilia, autoimmunity or neoplasms. These changes should be excluded, but most cases remain idiopathic, which contributes to the therapeutic difficulty. The authors intend to emphasize the importance of the Dermatologist in the diagnosis of a probably under-recognized disease that causes significant morbidity.

KEYWORDS - Arterial Occlusive Diseases; Leg Ulcer; Livedo Reticularis; Skin Ulcer.

\section{INTRODUÇÃO}

A vasculopatia livedóide (VL) é uma dermatose incomum e desafiante com uma evolução crónica e recidivante. Apesar das designações mais antigas, não se trata de uma vasculite, mas sim de uma patologia trombo-oclusiva que se deve à deposição e formação de trombos de fibrina na microcirculação dérmica.

A VL pode ser classificada como primária (idiopática) ou secundária a diversas patologias autoimunes, trombofilias (hereditárias ou adquiridas) ou neoplasias (hematológicas ou sólidas).

Clinicamente caracteriza-se pela presença de máculas e pápulas eritemato-purpúricas punctiformes/lenticulares com atingimento preferencial do terço inferior das pernas e que cursa com o aparecimento de úlceras desproporcionalmente dolorosas que cicatrizam de forma lenta, sob a forma de atrofia branca. ${ }^{1,2}$

Com este trabalho pretendeu-se fazer uma caracterização
Correspondência: Rui Pedro Santos Hospital de Braga - Braga, Portugal Rua de Santa Bárbara ${ }^{\circ} 52$

4435-595 Baguim do Monte, Portugal

E-mail:drruisantos@hotmail.com

DOI: https://dx.doi.org/10.29021/spdv.76.3.916
Recebido/Received

11 Março/March 2018

Aceite/Accepted

01 Abril/April 2018 


\section{Artigo Original}

clínica e laboratorial dos casos de VL seguidos no Serviço de Dermatologia e Venereologia do Hospital de Braga entre os anos de 2007 e 2014, bem como avaliação da resposta à terapêutica.

\section{CASOS CLÍNICOS}

Neste estudo retrospetivo foram descritos cinco doentes, dois do sexo feminino e três do sexo masculino. As idades atuais estavam compreendidas entre os 23 e os 53 anos (média de 39,2 anos). A idade à data do início dos sintomas variava entre os 19 e os 50 anos (média de 32,4 anos) e a idade á data do diagnóstico variava entre os 21 e os 52 anos (média de 36 anos) sendo que o tempo médio decorrido até ao diagnóstico foi de 3,6 anos (variando entre 2 a 7 anos) (Tabela 1).

Dos antecedentes pessoais, destacavam-se em dois doentes do sexo masculino a presença de hábitos tabágicos e em um doente história de artrite seronegativa.

Os antecedentes familiares eram irrelevantes, não existindo história de trombofilias associadas.

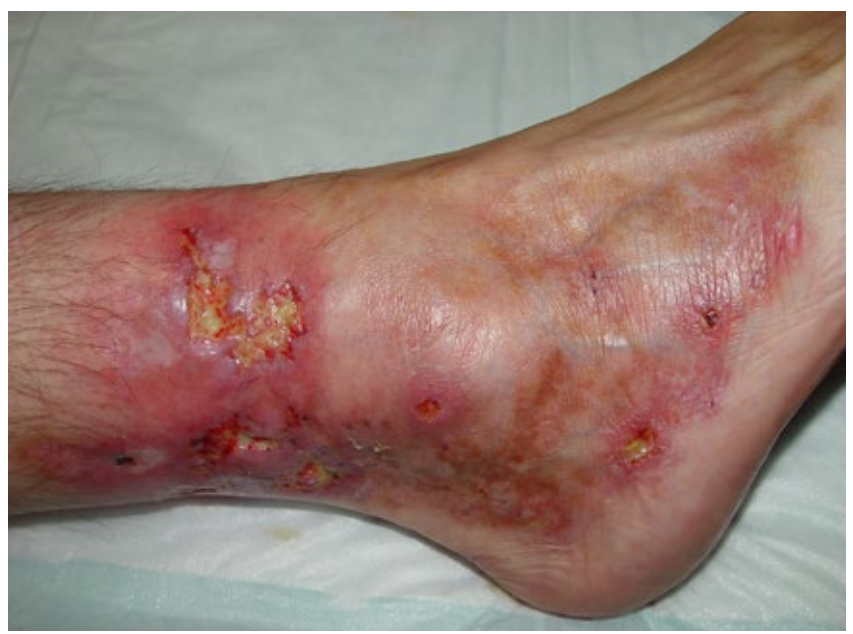

Figura 1 - Úlceras profundas punctiformes e outras maiores bem delimitadas da região peri-maleolar assim como cicatrizes deprimidas de ulcerações prévias e áreas de atrofia branca com hiperpigmentação em redor (caso 4).

Tabela 1 - Caracterização da população do estudo.

\begin{tabular}{|c|c|c|c|c|c}
\hline Doente & Sexo & Idade (anos) & $\begin{array}{c}\text { Idade no início dos } \\
\text { sintomas (anos) }\end{array}$ & $\begin{array}{c}\text { Idade à data de } \\
\text { diagnóstico (anos) }\end{array}$ & $\begin{array}{c}\text { Associaçóes } \\
\text { relevantes }\end{array}$ \\
\hline Caso 1 & M & 42 & 31 & 36 & - \\
\hline Caso 2 & F & 53 & 50 & 52 & - \\
\hline Caso 3 & F & 47 & 38 & 45 & Artrite seronegativa \\
\hline Caso 4 & M & 31 & 24 & 26 & Fumador \\
\hline Caso 5 & M & 23 & 19 & 21 & Fumador \\
\hline & $3 \mathrm{M}: 2 \mathrm{~F}$ & $-\mathrm{X}=39,2$ & $-\mathrm{X}=32,4$ & $-\mathrm{X}=36$ & \\
\hline
\end{tabular}

F- Feminino; M- Masculino

Clinicamente, todos os doentes tiveram uma apresentação clássica da doença: forma crónica e recidivante cursando com ulcerações dolorosas esporádicas localizadas aos membros inferiores e originando o padrão de cicatrização de atrofia branca (Figs. 1 e 2). Um dos doentes apresentava ainda um livedo racemoso envolvendo os membros inferiores, bilateralmente, até ás coxas (Fig. 3).

Apesar do diagnóstico ter sido estabelecido na Consulta de Dermatologia, a proveniência dos doentes foi variada: dois da consulta de Cirurgia Vascular, um da consulta de Reumatologia, um da consulta de Medicina Geral e Familiar e um da consulta de Dermatologia de outro hospital.

Todos os doentes foram avaliados em consulta de $\mathrm{Ci}$ rurgia Vascular para exclusão de doença venosa crónica como principal agente etiológico da dermatose.

Foi realizado o estudo de trombofilias (incluindo antitrombina III, proteína C, proteína S, mutação do Factor V

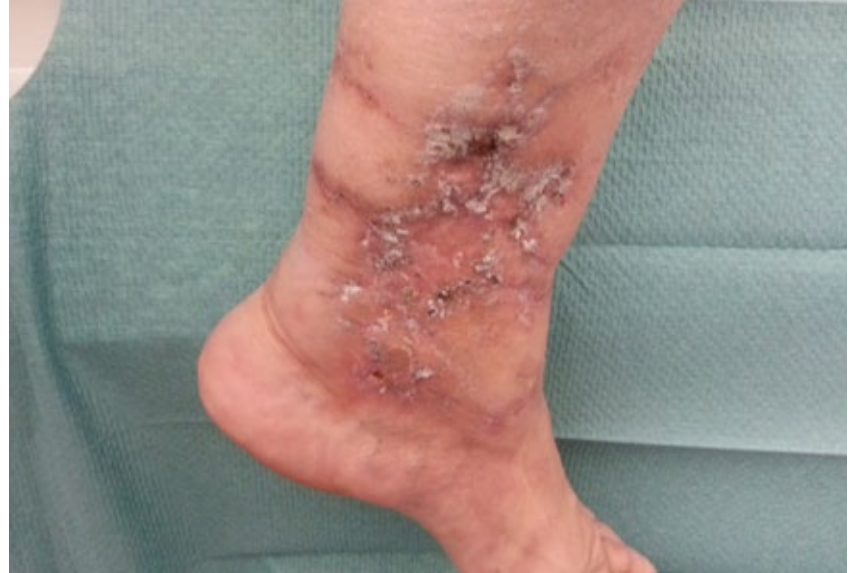

Figura 2 - Fase quiescente de VL com lesões crostosas e atrofia branca com hiperpigmentação periférica, eritema e telangiectasias (caso 3). 


\section{Artigo Original}

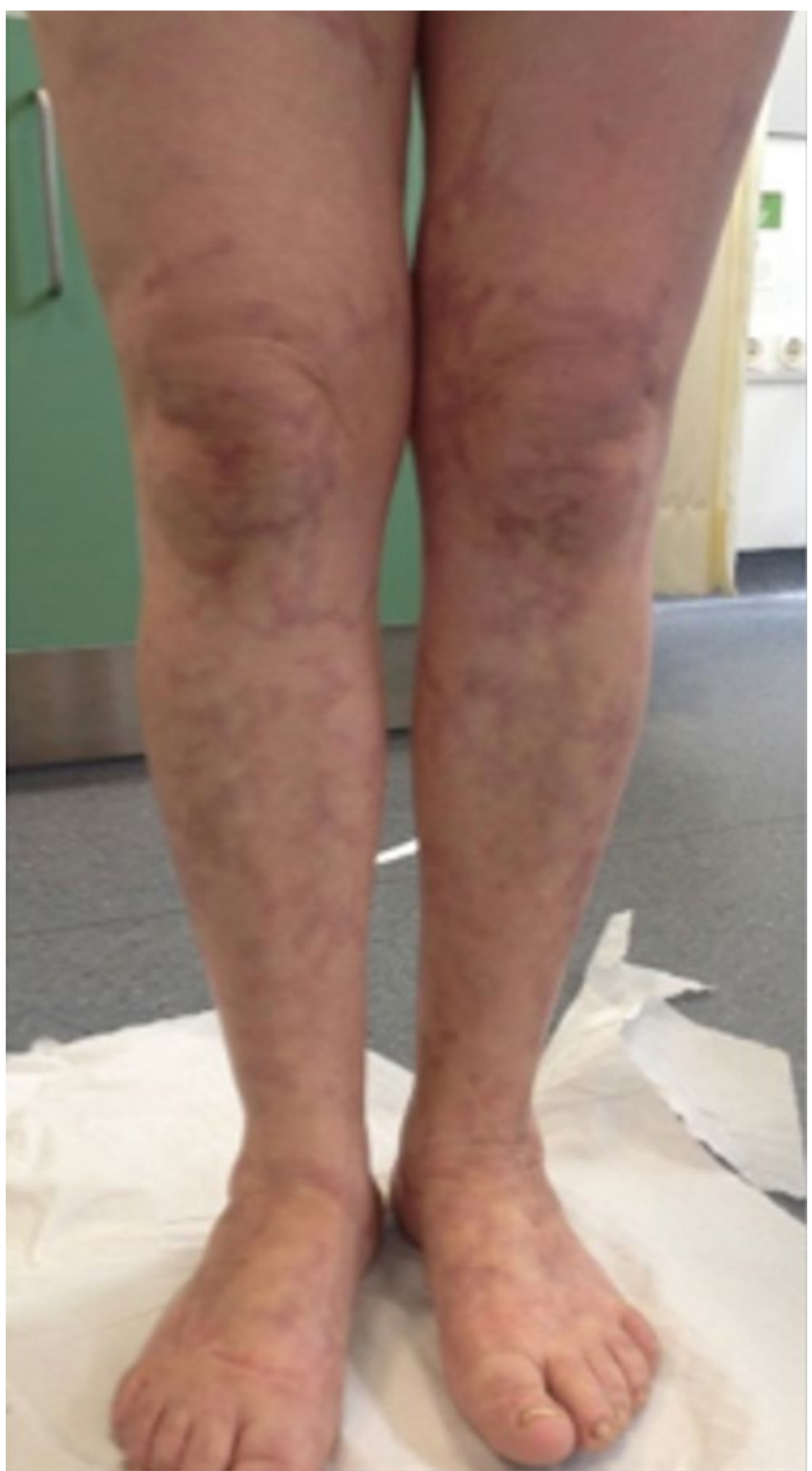

Figura 3 - Livedo racemoso (caso 2)

de Leiden, mutação G20210A da protrombina, mutação do gene MTHFR, homocisteinémia, anticorpos antifosfolípidos (anticoagulante lúpico, anticardiolipina), D-dímeros, fibrinogenemia, fatores VIII, IX e XI da coagulação, estudo do complemento, electroforese e imunoeletroforese, crioglobulinas, lipoproteína $A, I N R)$ assim como estudo imunológico (ANA, anti-dsDNA, anti-ENA, ANCA, factor reumatoide) e serologias infeciosas ( $\mathrm{VIH} \mathrm{I} \mathrm{e} \mathrm{II,} \mathrm{hepatite} B$, hepatite $C$, VDRL e TPHA) em todos os doentes para exclusão de causas secundárias. Desse estudo, destaca-se um doente com ANA 1/40 com padrão mosqueado fino, um doente com diminuição ligeira da proteína $S$, não confirmada em análise subsequente e D-dímeros de $682 \mathrm{ng} /$ $\mathrm{mL}(\mathrm{N}<500 \mathrm{ng} / \mathrm{mL})$, e dois doentes com mutação do gene

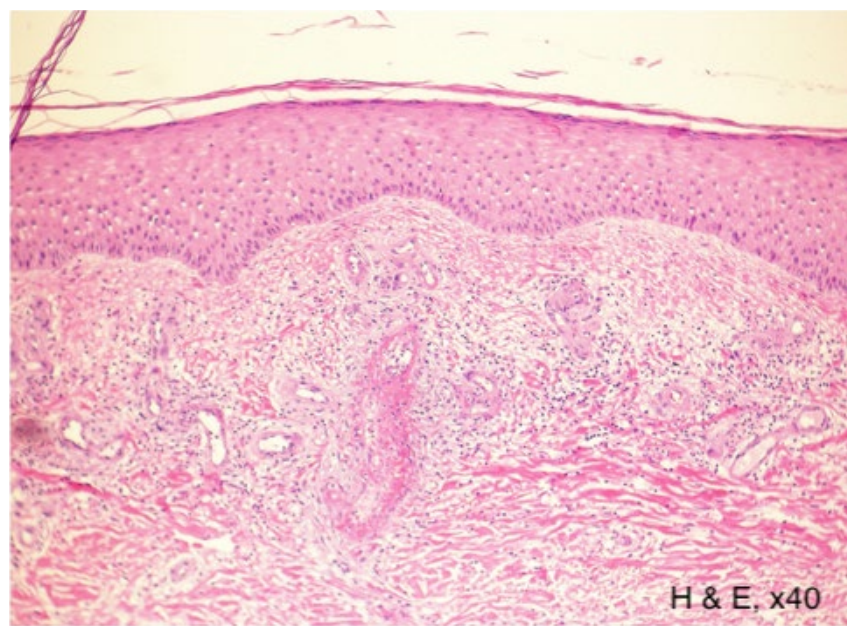

Figura 4 - Exame histopatológico (caso 3): proliferação vascular no plexo capilar superficial, com trombose luminal constituída por coágulos de fibrina e sem fenómenos de vasculite, aspetos característicos de vasculopatia livedóide (H\&E 40x).

MTHFR. Destes últimos, um apresentava uma heterozigotia A 1298 C e outro uma heterozigotia composta (A1298C e C677T). No entanto, nenhum destes doentes apresentava hiperhomocisteinémia associada, pelo que as mutações do gene MTHFR foram excluídas como causa de hipercoagulabilidade.

A biópsia cutânea foi realizada em quatro doentes. Em três deles, apresentava alterações compatíveis com o diagnóstico de vasculopatia livedóide (proliferação vascular no plexo capilar superficial, com frequente trombose luminal constituída por coágulos de fibrina, sem lesões de vasculite) (Fig. 4) e, num outro, revelou-se inespecífica.

As estratégias terapêuticas adotadas foram variadas (Tabela 2). Diferentes classes farmacológicas e com diferentes mecanismos de ação foram utilizados quer isoladamente quer em associação. A pentoxifilina foi utilizada em todos os doentes seguindo-se os fármacos antiplaquetários (ácido acetilsalicílico e dipiridamol) e os venotrópicos (bioflavonóides, diosmina e vaccinium myrtillus) utilizados em quatro doentes. Outras terapêuticas foram utilizadas em dois doentes (imunoglobulina endovenosa (lgEV), bloqueadores dos canais de cálcio - nifedipina, e imunossupressores - prednisolona, metotrexato e azatioprina) ou em apenas um doente (anticoagulantes - varfarina e heparina de baixo peso molecular, sulfona, danazol e suplementos vitamínicos - acido fólico, vitamina B12 e vitamina B6). Os efeitos secundários da medicação instituída, relatados pelos doentes, limitaram-se a um caso de cefaleias provocadas pela pentoxifilina e um caso de meningite assética atribuída à IgEV que naturalmente justificaram a interrupção das terapêuticas em causa.

Para além da terapêutica farmacológica foi também recomendada a cessação tabágica aos dois doentes fumadores, inclusivamente com referenciação para consulta apropriada. 


\section{Artigo Original}

Tabela 2 - Terapêutica usada nos 5 doentes do estudo.

\begin{tabular}{|c|c|c|c|c|c|}
\hline & Caso 1 & Caso 2 & Caso 3 & Caso 4 & Caso 5 \\
\hline \multicolumn{6}{|l|}{ Anticoagulantes } \\
\hline Varfarina & & & $x$ & & \\
\hline HBPM & & & $x$ & & \\
\hline \multicolumn{6}{|l|}{ Anti-plaquetários } \\
\hline AAS & $x$ & $x$ & $x$ & $x$ & \\
\hline Dipiridamol & & & $x$ & & \\
\hline Pentoxifilina & $x$ & $x$ & $x$ & $x$ & $x$ \\
\hline \multicolumn{6}{|l|}{ Venotrópicos } \\
\hline Bioflavenóides & & $x$ & $x$ & $x$ & $x$ \\
\hline Diosmina & & $x$ & & $x$ & \\
\hline Vaccinium myrtillus & & $x$ & & & \\
\hline \multicolumn{6}{|l|}{ Imunossupressores } \\
\hline Prednisolona & $x$ & & $x$ & & \\
\hline MTX & & & $x$ & & \\
\hline Azatioprina & & & $x$ & & \\
\hline \multicolumn{6}{|l|}{ Outros } \\
\hline IgEV & $x$ & & & $x$ & \\
\hline Dapsona & $x$ & & & & \\
\hline Nifedipina & & $x$ & & $x$ & \\
\hline Vitaminas (Ac. Fólico, B6 e B12) & & & $x$ & & \\
\hline Danazol & & & & $x$ & \\
\hline TOTAL & 5 & 6 & 10 & 7 & 2 \\
\hline
\end{tabular}

HBPM - heparina de baixo peso molecular; AAS - ácido acetil-salicílico; MTX - metotrexato; lgEV - imunoglubulina endovenosa

Apesar da terapêutica instituída, todos os doentes mantêm alguns episódios ocasionais de ulcerações dolorosas. No entanto, apenas um doente apresenta um controlo verdadeiramente insatisfatório da doença, com episódios de ulcerações frequentes e prolongados. Este último doente é também aquele em que mais fármacos foram utilizados na tentativa de controlo da doença (inclusivamente o único em que foram utilizados metotrexato, azatioprina e anticoagulantes isoladamente e em associação). O esquema que melhores resultados apresentou foi a associação de metotrexato, ácido fólico e varfarina.

No decurso do seguimento destes doentes (desde o diagnóstico até 2014), destacamos o diagnóstico de uma polineuropatia periférica sensitivo-motora em dois doentes, que poderá estar enquadrada no contexto da $\mathrm{VL}$, e ainda um terceiro doente com parestesias dos membros inferiores, ainda em estudo.

\section{DISCUSSÃO}

A vasculopatia livedóide (VL) é uma dermatose de difícil abordagem. Conheceu ao longo do tempo uma toponímia variada: "vasculite livedóide", "vasculite hialinizante segmentar", "livedo reticular com úlceras de verão", "atrofia branca de Milian", "atrofia branca em placas" e "PPURPLE" (painful purpuric ulcers with reticular pattern of the lower extremities) pelo que a pesquisa bibliográfica sobre esta patologia é algo complexa. ${ }^{3,4}$

A VL é uma dermatose incomum com uma prevalência estimada de 1:100.000 habitantes por ano afetando sobretudo mulheres (proporção mulher-homem de 2,4-3:1). 
Acomete sobretudo a faixa etária entre os 15 e os 50 anos de idade com uma idade média de 32 anos. ${ }^{1,5}$ No nosso estudo, os valores são algo díspares uma vez que existiu uma predominância do sexo masculino (proporção mulher-homem de 2:3). No entanto a idade média de aparecimento dos sintomas foi de 32,4 anos e, portanto, de acordo com a literatura. Tal como evidenciado nos nossos doentes (média de 3,6 anos, variando entre 2 a 7 anos), o período entre o primeiro sintoma e o diagnóstico é geralmente longo e causa de grande sofrimento ao paciente. Estes dados epidemiológicos são obviamente enviesados pelo reduzido tamanho da amostra.

A atrofia branca $(A B)$ foi primeiramente descrita por Milian em 1929 como uma forma particular de atrofia cutânea designada "atrofia branca em placas" descrevendo áreas nacaradas e atróficas dos membros inferiores circundadas por áreas de hiperpigmentação e telangiectasias punctiformes. ${ }^{6}$ Apesar de ainda hoje a etiopatogenia da VL permanecer controversa, parece universalmente aceite que a $A B$ é uma descrição morfológica de um padrão de cicatrização, não exclusivo da VL mas partilhado por muitas outras patologias como insuficiência venosa crónica, lúpus eritematoso sistémico ou dermatomiosite. ${ }^{2}$ Desta forma não é correto utilizar os termos $A B$ e VL como sinónimos. ${ }^{7}$

A VL é uma dermatose trombo-oclusiva que cursa com a formação de trombos de fibrina no lúmen dos vasos da microcirculação dérmica, não existindo evidência histológica de inflamação e, portanto, o termo "vasculite" não deve ser empregue para descrever esta patologia.

Uma vez que as causas da formação desses trombos ainda não são completamente conhecidas, existem muitos casos designados idiopáticos. No entanto, as possíveis causas secundárias de hipercoagulabilidade (trombofilias - congénitas e adquiridas, doenças autoimunes e neoplasias) devem ser estudadas e pesquisadas se houver indícios clínicos da existência dessas patologias (Tabela 3). ${ }^{1}$ No caso dos doentes do nosso trabalho, foi feita a pesquisa laboratorial de trombofilias e principais doenças autoimunes não tendo sido encontradas relações relevantes.

Assim sendo, podemos considerar que os nossos doentes apresentavam formas idiopáticas da doença. Isto não significa que não exista uma alteração do sistema de coagulação ou fibrinólise, e apenas que essa alteração ainda não é, pelos meios ao nosso dispor, passível de identificar laboratorialmente.

A VL apresenta uma evolução crónica com períodos de agudização e ulceração recorrentes. Caracteriza-se pela presença de lesões, inicialmente eritemato-purpúricas punctiformes ou lenticulares, dolorosas, nos membros inferiores (em especial nas regiões maleolares e dorso dos pés). ${ }^{7}$ Eventualmente, surge ulceração dessas lesões que evoluem com uma cicatrização lenta (semanas a meses) originando cicatrizes estreladas, atróficas e nacaradas $(A B)$, hiperpigmentação periférica e telangiectasias punctiformes. ${ }^{7}$ A presença de livedo racemoso (manchas

\section{Tabela 3 - Etiopatogenia da Vasculopatia Livedóide (adaptado de Criado PR et al').}

Primária

Idiopática

Doença do tecido conjuntivo

- Lúpus eritematoso sistémico

- Esclerose sistémica

- Artrite reumatóide

- Doença mista do tecido conjuntivo

Trombofilias hereditárias

- Mutação do factor V de Leyden

- Mutação do gene da protrombina

- Mutação do inibidor 1 do activador do plasminogénio tecidual

- Mutação da metiltetrahidratofolato redutase (MTHFR)

- Défice de antitrombina III

Secundária

- Défice de proteína C

- Défice de proteína S

- Elevação da lipoproteína A

Trombofilias adquiridas

- Síndrome de anticorpo anti-fosfolipido

- Criofibrinogenemia

- Hiperhomocisteinemia

Neoplasias

Hematológicas

- Órgãos sólidos 


\section{Artigo Original}

eritematosas com padrão reticular irregular que desaparecem com a diascopia) pode também ser observada nestes doentes, como num dos nossos casos, e pode ser considerada como uma predisposição para o desenvolvimento de $\mathrm{VL} .{ }^{5,7} \mathrm{~A}$ VL tem geralmente um atingimento bilateral dos membros inferiores, como em todos os nossos doentes.

A dor é uma característica constante e marcante desta patologia, cursa com agudização durante os períodos de ulceração, condiciona sofrimento intenso e limitação das atividades de vida diária dos doentes.' A natureza da dor parece ser isquémica em resultado da oclusão vascular. ${ }^{1}$ Esta apresentação clássica da doença verificou-se em todos os doentes do nosso estudo.

Para além do quadro descrito, alguns doentes apresentam queixas de parestesia ou hiperestesia. ${ }^{1,8}$ Estas queixas parecem enquadrar-se num quadro de mononeuritis multiplex e foi sugerido que a oclusão dos vasa nervorum e subsequente isquemia nervosa será a causa. ${ }^{8-10} \bigcirc$ envolvimento neurológico nesta condição é raro e pouco descrito na literatura. ${ }^{8-10}$ Numa série de casos publicada com 70 doentes foi descrito que $9 \%$ desses doentes apresentava evidência de neuropatia periférica no exame clinico e estudos de condução. ${ }^{8,10}$ Os sintomas relatados em todos os casos eram inteiramente sensitivos. De entre os cinco doentes do nosso trabalho, destaca-se o diagnóstico de neuropatia periférica sensitiva, durante a evolução da doença, em dois doentes, sendo que um terceiro doente apresenta queixas de parestesia dos membros inferiores, estando atualmente em estudo.

É sugerido por alguns autores que perante um quadro clinico típico de $\mathrm{VL}$, não existe necessidade de realização de biópsia cutânea. ${ }^{1,11}$ Contudo, o estudo histopatológico pode ser útil não apenas na confirmação do diagnóstico de VL mas também na exclusão de outros diagnósticos diferenciais., ${ }^{1,5}$ A biópsia cutânea, quando efetuada, deve obter uma amostra de pele representativa desde a epiderme até, pelo menos, à junção dermo-hipodérmica. ${ }^{7} \mathrm{Na}$ $\mathrm{VL}$, o atingimento vascular ocorre na derme superficial e média (ocasionalmente na derme profunda) mas a representação da junção dermo-hipodérmica faz-se necessária para exclusão de outros diagnósticos, nomeadamente poliarterite nodosa (PAN). ${ }^{1}$ Histologicamente, a VL caracteriza-se pela deposição de material fibrinóide no lúmen vascular dos vasos da derme, hialinização segmentar da parede vascular, enfartes teciduais e ausência de vasculite verdadeira (infiltrado linfocitário perivascular mínimo).1,12 A imunofluorescência direta demonstra geralmente deposição de imunoglobulinas, fibrina e componentes do complemento, no entanto estes achados não são específicos da VL. ${ }^{11}$

A VL deve ser distinguida de outras patologias que cursem com a formação de úlceras nos membros inferiores, nomeadamente PAN, vasculite de pequenos e médios vasos, pioderma gangrenoso, necrose induzida por varfarina e insuficiência venosa crónica. ${ }^{7} \bigcirc$ principal diagnóstico diferencial, contudo, é a poliarterite nodosa cutânea. ${ }^{7}$
Para uma confirmação diagnóstica de PAN é necessária uma biópsia cutânea profunda.

Um diagnóstico correto de VL implica, geralmente, a associação de dados da anamnese, exame físico, parâmetros laboratoriais e histopatológicos. ${ }^{1,7}$ Uma vez estabelecido o diagnóstico de VL impõe-se um estudo dirigido às potenciais causas secundárias da doença. ${ }^{1}$ Assim, é importante avaliar a presença de doenças autoimunes, trombofilias (congénitas e adquiridas), paraproteinémia e associações infeciosas (serologias para hepatite B e C, assim como $\mathrm{VIH}$ ) e outras causas de hipercoagulabilidade. ${ }^{1}$ Nos nossos doentes, um estudo aprofundado de causas de hipercoagulabilidade foi efetuado. No entanto, desse estudo, apenas relevamos a presença, em dois doentes de mutações em heterozigotia do gene MTHFR que foi excluída como causa de hipercoagulabilidade e trombose por níveis de homocisteinémia normais.

Alguns autores sugerem que a investigação destes fatores de hipercoagulabilidade apenas deve ser efetuada se existirem indícios clínicos pessoais ou familiares da possível existência dessas coagulopatias. ${ }^{7}$ Isto porque a identificação destas causas de hipercoagulabilidade na VL, atualmente, se reveste de pouco significado terapêutico.

A evidência da eficácia da terapêutica da VL é limitada e atualmente não existem normas orientadoras para o tratamento. ${ }^{7}$ A própria história natural da doença, com o seu carácter recidivante e recorrente dificulta a avaliação da eficácia da terapêutica instituída. Vários tratamentos têm sido propostos e utilizados para o tratamento da VL.

O tratamento adequado das úlceras e a abordagem terapêutica da dor deve ser considerada tão ou mais importante que o tratamento sistémico da VL. Para o componente neuropático da dor tem sido sugerida a utilização de antidepressivos tricíclicos, gabapentina, pregabalina ou carbamazepina, enquanto para o componente nociceptivo da dor é sugerida a utilização da escada da dor da Organização Mundial da Saúde (OMS). ${ }^{13}$

Dado o possível papel de mecanismos trombogénicos na etiopatogenia da VL, têm sido usados agentes com função anti-plaquetária (ácido acetilsalicílico, dipiridamol, clopidogrel, ticlopidina) e anticoagulante (heparina de baixo peso molecular, heparina não-fracionada, antagonistas da vitamina K) com algum sucesso. 1,5,11,14 Estudos recentes demonstram que os anticoagulantes constituem uma terapêutica efetiva e bem tolerada para pacientes com VL. ${ }^{5}$

Outras terapêuticas utilizadas são a pentoxifilina (com o objetivo de diminuir a viscosidade do sangue), fármacos com atividade fibrinolítica (p.e. danazol, alteplase), PUVA, ciclosporina $A$, IgEV ou a oxigenioterapia hiperbárica com resultados variáveis. 1,15-18 Por vezes, corticosteroides sistémicos são usados na terapêutica da VL com efeitos controversos. ${ }^{11}$ Existem também relatos de terapêuticas com bloqueadores dos canais de cálcio (nifedipina) e com imunossupressores. ${ }^{11}$ A terapêutica combinada é também uma opção cada vez mais utilizada. 


\section{Artigo Original}

A única situação em que a identificação de um fator procoagulante parece influenciar a decisão terapêutica é no caso da hiperhomocisteinémia. ${ }^{19}$ Nessa situação, a VL parece responder bem ao tratamento com ácido fólico e vitaminas do complexo B. ${ }^{19}$ Nenhum dos doentes avaliados neste trabalho apresentava hiperhomocisteinémia. As abordagens terapêuticas nestes cinco doentes foram múltiplas, quer isoladamente quer em associação (Tabela 2).

Para além das medidas farmacológicas, a cessação tabágica deve ser encorajada. ${ }^{14}$ Dos doentes do nosso estudo, dois eram fumadores e apesar de explicados os benefícios da cessação, ambos mantêm os hábitos tabágicos.

\section{CONCLUSÃO}

Em suma, estes casos ilustram a dificuldade diagnóstica e terapêutica na abordagem da VL. O facto de a etiopatogenia da doença ainda não estar devidamente elucidada, dificulta a identificação de alvos terapêuticos e por conseguinte a terapêutica continua a basear-se essencialmente em séries de casos e consensos clínicos. Conseguiu-se demonstrar, mesmo com poucos doentes, as dificuldades em atingir um bom controlo da doença mesmo recorrendo a uma grande panóplia de recursos terapêuticos. Mesmo nos casos considerados com bom controlo, os doentes mantêm episódios ocasionais de ulcerações dolorosas.

Este trabalho tem como mérito relembrar esta patologia muitas vezes subdiagnosticada, com tempo médio até ao diagnóstico elevado e que condiciona sofrimento e limitações importantes para as atividades de vida diária dos doentes.

Conflitos de interesse: Os autores declaram não possuir conflitos de interesse.

Suporte financeiro: $O$ presente trabalho não foi suportado por nenhum subsídio ou bolsa.

Confidencialidade dos dados: Os autores declaram ter seguido os protocolos do seu centro de trabalho acerca da publicação dos dados de doentes.

Protecção de pessoas e animais: Os autores declaram que os procedimentos seguidos estavam de acordo com os regulamentos estabelecidos pelos responsáveis da Comissão de lnvestigação Clínica e Ética e de acordo com a Declaração de Helsínquia da Associação Médica Mundial

Conflicts of interest: The authors have no conflicts of interest to declare.

Financing Support: This work has not received any contribution, grant or scholarship.

Confidentiality of data: The authors declare that they have followed the protocols of their work center on the publication of data from patients.

Protection of human and animal subjects: The authors declare that the procedures followed were in accordance with the regulations of the relevant clinical research ethics committee and with those of the Code of Ethics of the World Medical Association (Declaration of Helsinki).

\section{REFERÊNCIAS}

1. Criado PR, Rivitti EA, Sotto MN, Valente NY, Aoki V, Carvalho JF, et al. Livedoid vasculopathy: an intringuing cutaneous disease. An Bras Dermatol. $2011 ; 86: 961-77$.

2. Poletti NM, Moreno González JL, Santacruz Torres A. Vasculopatía livedoide: significado actual. Comunicación de dos casos. Dermatología Rev Mex. 2008;52:175-81.

3. Papi M, Didona B, De Pita O, Frezzolini A, Di Giulio S, De Matteis $W$, et al. Livedo vasculopathy vs small vessel cutaneous vasculitis: cytokine and platelet P-selectin studies. Arch Dermatol. 1998;134:447-52.

4. Feldaker M, Hines EA Jr., Kierland RR. Livedo reticularis with summer ulcerations. AMA Arch Derm. 1955;72:31-42.

5. Di Giacomo TB, Hussein TP, Souza DG, Criado PR. Frequency of thrombophilia determinant factors in patients with livedoid vasculopathy and treatment with anticoagulant drugs--a prospective study. J Eur Acad Dermatol Venereol. 2010;24:1340-6.

6. Gray HR, Graham JH, Johnson W, Burgoon CF Jr. Atrophie blanche: periodic painful ulcers of lower extremities. A clinical and histopathological entity. Arch Dermatol. 1966;93:187-93.

7. Alavi A, Hafner J, Dutz JP, Mayer D, Sibbald RG, Criado $P R$, et al. Livedoid vasculopathy: an in-depth analysis using a modified Delphi approach. J Am Acad Dermatol. 2013;69:1033-42 el.

8. Alix JJ, Hadiivassiliou M, Ali R, Slater D, Messenger AG, Rao DG. Sensory ganglionopathy with livedoid vasculopathy controlled by immunotherapy. Muscle Nerve. 2015;51:296-301.

9. Toth C, Trotter M, Clark A, Zochodne D. Mononeuropathy multiplex in association with livedoid vasculitis. Muscle Nerve. 2003;28:634-9.

10. Kim JE, Park SY, Sinn DI, Kim SM, Hong YH, Park KS, et al. Ischemic neuropathy associated with livedoid vasculitis. J Clin Neurol. $2011 ; 7: 233-6$.

11. Maessen-Visch MB, Koedam MI, Hamulyak K, Neumann HA. Atrophie blanche. Int J Dermatol. 1999;38:161-72.

12. Kutzner $\mathrm{GH}$. Therapeutic use of low molecular weight heparin for capillaritis alba. Phlebologie. 2008;37:25965.

13. Woo KY, Abbott LK, Librach L. Evidence-based approach to manage persistent wound-related pain. Curr Opin Support Palliat Care. 2013;7:86-94.

14. Hairston BR, Davis MD, Pittelkow MR, Ahmed I. Livedoid vasculopathy: further evidence for procoagulant pathogenesis. Arch Dermatol. 2006;142:1413-8.

15. Deng A, Gocke CD, Hess J, Heyman M, Paltiel M, Gaspari $A$. Livedoid vasculopathy associated with plasminogen activator inhibitor-1 promoter homozygosity (4G/4G) treated successfully with tissue plasminogen activator. Arch Dermatol. 2006;142:1466-9. 


\section{Artigo Original}

16. Tuchinda C, Leenutaphong V, Sudtim S, Lim HW. Refractory livedoid vasculitis responding to PUVA: a report of four cases. Photodermatol Photoimmunol Photomed. 2005;21:154-6.

17. Kreuter A, Gambichler T, Breuckmann F, Bechara FG, Rotterdam S, Stucker $M$, et al. Pulsed intravenous immunoglobulin therapy in livedoid vasculitis: an open trial evaluating 9 consecutive patients. J Am Acad Dermatol. 2004;51:574-9.

18. Yang $\mathrm{CH}, \mathrm{Ho} \mathrm{HC}$, Chan YS, Liou LB, Hong HS, Yang LC.
Intractable livedoid vasculopathy successfully treated with hyperbaric oxygen. Br J Dermatol. 2003;149:64752.

19. Rampf J, Sunderkotter C, Hirschfeld G, Scharffetter-Kochanek K, Weiss JM. Methylenetetrahydrofolate reductase polymorphism associated with moderate hyperhomocysteinaemia in a patient with livedo vasculopathy: treatment with vitamin supplementation and low molecular weight heparin. $\mathrm{Br} J$ Dermatol. 2006;155:850-2. 